\title{
What helps? Women engineers' accounts of staying on
}

We have considerable understanding of the obstacles that women engineers encounter and the reasons that they leave the field, but we know less about what enables them to remain. Adopting an interpretivist approach, this article examines how a group of British women engineers in two FTSE 100 companies account for 'staying on' in their male dominated work settings. We delineate four specific forms of help that facilitate women's retention in the field. We argue that exposure to help leads to women developing a habitus that enables them to continue working in engineering. To conclude we draw on our findings to outline HR practices that will facilitate supportive relationships in the workplace and pave the way towards developing more positive organisational climates.

Key words: help, support, retention, women, engineering, career, habitus

\section{Introduction}

The field of engineering has a significant gender-based retention problem. Despite all of the efforts channelled towards getting women to study STEM subjects, close to 40 percent of those who gain engineering degrees eventually decide to leave the profession (Fouad and Singh, 2011). The majority of scholarly work focuses on explaining exit, providing insights into the effects of inhospitable workplace climates, lack of opportunities for advancement (Fouad et al. 2015), unclear career paths (Hewlett et al. 2008) and difficulties in balancing work and family roles (Bagilhole et al., 2007). However, a smaller body of work examines those women engineers who stay on in their fields, either within an organisation or across work settings. Some studies identify personal aspects, such as confidence (Ayre et al., 2013; Plett et al., 2009; Hughes, 2011) and hope for the future (Buse et al. 2013), that enable exceptional 
women to remain in engineering. Fewer contributions highlight the significance of context, emphasising the importance of support (Fouad et al, 2015; Ayre et al, 2013). Notwithstanding the important insights they offer, however, we have very little qualitative understanding of how women experience support and how it influences their thinking and action.

In this article, we adopt an interpretivist (Johnson and Duberley, 2000) perspective to examine how a group of British women engineers account for staying on in their fields. Our focus is on women's interpretations. Explaining why they remained when many women engineers left, our respondents highlighted personalised forms of help received from others within their organisations. Notably, respondents talked about help as largely ad hoc encounters that they felt lucky to receive.

We draw on Bourdieu's $(1984,1990)$ notion of habitus to establish how the specific forms of help that women identify enable them to stay on in engineering. Habitus is a schema of internalised, embodied ways of thinking, feeling, and acting, which is shaped by social experiences (Bourdieu, 1984; 1990). We argue that it provides a useful framework for understanding how some women engineers develop ways of operating that, taken together, facilitate their persistence in the field. This paper addresses the central question: How does help foster the development of an engineering habitus which encourages women to stay on in the profession? By investigating this issue, we aim to contribute new insights into the interplay of the individual and their social context in women engineers' career-making, a perspective which the extant literature has been slow to address. 
In what follows, we review the literature on women's careers in engineering, highlighting limitations in our current understandings of why some women engineers stay on when so many choose to leave. Next, we introduce our empirical study and explain our use of the concept of habitus in our analysis (Reay, 2016; Dumais, 2002). Our findings provide insights into four distinct forms of support that women engineers identified as helpful for them to stay in the field. Our study extends existing understandings of women's retention in engineering, showing how participating in supportive relationships in the workplace facilitates the development of an engineering habitus which makes 'staying on' a possibility. We conclude by highlighting the importance of support being equitably accessible to all employees, identifying $H R$ practices that may facilitate supportive relationships in the workplace and outlining the agenda for further research.

\section{Staying on in engineering: the story so far}

There is a consensus that engineering cultures are influenced by assumptions that prioritise stereotypically masculine attributes, characteristics and actions over those that are stereotypically feminine (Hatmaker, 2013; Powell et al. 2009). For instance, drawing on an interview-based study of Australian women engineers across the range of disciplines, Gill et al. (2008) argue that engineering as a profession has been constructed as a 'man's world' where the size and scale of projects as well as language and patterns of understanding (e.g. prevalent metaphors) exclude women (Mills et al. 2008). Similarly, in an ethnographic study of oil engineering, Faulkner (2009) argues that interactions are characterised by fraternal markers of familiarity and bonding. In her study she found that when engineers' conversations strayed beyond the immediate task in hand, they often reflected shared subjectivities around technology and/or typically masculine topics such as football. In such environments women 
remain isolated (Watts, 2010), struggle to secure informal support and encounter barriers to social networks (Roth, 2006). Furthermore, as a minority in a heavily masculine profession, women are often stereotyped as technically incompetent (Faulkner, 2009; Powell et al. 2009) and kept away from core knowledge clusters (Greed, 2000).

The gendered nature of engineering is also reflected in a long working hours culture where incumbents are required to devote long hours and prioritise work above all other concerns (Watts, 2007; Servon and Vissers, 2011). Moreover, there are regular after-hours social gatherings in pubs and sports clubs (Bilmoria et al. 2014). Watts (2007) found that women who cannot conform to long hours cultures because of parenting responsibilities are made to feel conspicuous and, here again, as if they don't belong. Indeed, many women engineers eventually choose to leave the profession due to marginalisation, isolation, perception of a lack of opportunities for advancement (Hewlett et al. 2008), and/or difficulties in the management of childcare (Bagilhole et al. 2007; Fouad and Singh, 2011). While much of the existing literature has sought to uncover barriers to explain women engineers' high turnover rates, a few contributions examine retention. Some of this work focuses on explicating the personal characteristics that enable women to stay in the profession, while fewer contributions recognise the impact of the organisational context. In what follows, we will address individual and organisational factors in turn.

\section{Individual factors that facilitate staying on}

For women engineers, staying on appears to be a matter of confidence, competence, relational orientation and identity. In their research into Australian civil engineers, Ayre et al. (2013) argue that women who remain in the profession display high levels of self-belief. These 
women see themselves as good engineers, with the requisite skills and competence to do the job. Importantly, they feel that they belong in their organisations. Other scholars have similarly emphasised the mutuality of competence and confidence in women's continuation in engineering. For instance, in a qualitative study of female science and engineering students, Hughes (2011) suggests that individuals are encouraged to carry on when they are confident in their abilities and confidence leads to them attempting to further develop their expertise (Pierrakos et al, 2009).

Plett et al. (2011) introduce the concept of identity to this complex picture, arguing that staying on is less about women's characteristics or affective states, and more a matter 'seeing themselves as engineers'. Unfortunately, the authors do not examine the process through which women develop this identity. While the majority of literature on women engineers' persistence focuses on elucidating individual characteristics, a few important exceptions recognise the crucial role of the organisational context.

\section{Staying on and the role of organisational context}

Scholars have argued that the retention of women engineers is facilitated by supportive organisational cultures that make incumbents feel that they are recognised and accepted. In their study noted above, Ayre et al. (2013) argue that supportive work cultures must recognise and affirm women's as well as men's competence. Others maintain that organisational cultures must ensure that women feel accepted (Mills et al. 2006). However, within these studies, the conceptualisation of culture is generic, and authors do not specify what a 'supportive culture' might look like in practice.A few contributions provide more specific insights into support. For example, Ayre et al. (2013) highlight how professional 
acceptance and respect from male colleagues shape women's sense of belonging in the engineering field. They start to address how particular forms of support from 'other people' can lead to individual attributes that facilitate (sense of belonging) that facilitate retention. In a further development, drawing on findings generated in a comparative study of women who remain and leave the engineering field, Fouad et al. (2015) found that women who stay had received more 'content specific' support in terms of better opportunities for advancement than those who left. They suggest that this content specific support enables women to develop the competence they need to remain in the field. They also highlight how line managers' appreciation of women's domestic roles and responsibilities can lead them to challenge conventional views of engineering and motherhood as mutually exclusive. Fouad et al.'s (2015) study moves the field forward by identifying forms of support associated with women's retention in engineering.

Outside the literature on women in engineering, the significance of support for individuals' careers is widely recognised. For instance, the careers literature notes how support through informal mentorship is instrumental for women's progression in gendered organisations (Durbin and Tomlinson, 2014; Singh et al. 2002; Janssen et al. 2015; Ehrich, 2008; Swap et al., 2001; Allen et al., 2004; Underhill, 2006). However, while scholars (Ayre et al. 2013; Fouad et al. 2015) start to talk about the importance of examining specific forms of support and the interplay between the social context and individual, we have little in-depth understanding of how women engineers' experience support and how it influences their thinking and action. These are important lines of inquiry into the particular issue of staying on. 


\section{Social support}

The literature on social support (House et al. 1980) indicates that instrumental support (i.e. practical help) from supervisors (Bennet and Beehr, 2013) leads to job satisfaction (Harris et al. 2007) and motivation, even in very demanding jobs (Van Yperen and Hagedoorn, 2003), while information support from co-workers is associated with a reduction in role ambiguity, higher satisfaction and progression towards work goals (Chiaburu and Harrisson, 2008). Emotional support is seen as enhancing feelings of positive social standing (Tyler and Blader, 2000), and employees reporting higher levels of social support are seen as less likely to leave the workplace ( $\mathrm{Ng}$ et al. 2008). Scholars argue that the combination of instrumental and emotional support through embedded exchanges among co-workers can buffer the detrimental consequences of unfavourable organisational cultures (Duffy et al. 2002; Wu and Hu, 2009; Hayton et al. 2012). However, with a few notable exceptions (Fouad et al. 2015; Ayre et al. 2013), these insights have not been applied to women in engineering.

Engineering is a particularly revealing context to examine the role of support for women's careers because it is a heavily gendered context where women often remain in the margins. In this setting, support might make the difference between women engineers' staying and leaving. Focusing on the accounts' of women engineers in two FTSE 100 firms in the UK, our intention is to understand how specific forms of support facilitate women's retention in heavily gendered organisational cultures - cultures that are inhospitable to most women (Faulkner, 2009; Powell et al. 2009). We draw on Bourdieu's (1990) notion of habitus to do this. Within the concept of habitus, the individual and their context inform and help to shape one another (Colley et al. 2007). We therefore see habitus as a useful device to understand 
the interplay between the individual and the social context that is central to women's persistence on the engineering pipeline.

\section{Habitus}

Habitus is generally understood as a schema of cognitive structures (Robbins, 1991), psychic and mental schemes, socially constituted dispositions (Swartz, 2002) and embodied interiority (Silva, 2016) including emotions (Reay, 2004) and aspirations (Dumais, 2013) which is shaped by social experiences. It is strongly connected to field; a structured space which tends to be relatively autonomous and is characterised by specific logics of action (Bourdieu, 1988, p. 784). We can neither see nor measure a field except via its effects (Martin, 2003). The field tends to shape the habitus, while the habitus tends to shape perceptions of the field (Reay, 2004). Therefore, from this perspective the relationship between individuals and their social contexts is central.

Focusing on early socialisation, scholars have captured the effects of parents and families on habitus (Sullivan, 2001; De Graff et al. 2000). Indeed most scholars draw on habitus to explain social continuity and habitus has been criticised for being deterministic (see for example: DiMaggio, 1997; King 2000). However, Bourdieu (1990) denies this charge, arguing that the habitus is permeable and can incrementally change in response to new experiences. A key point about habitus is that perceptions of past experiences can be modified by present ones (Reay, 2004), and the present is shaped by the perceived future (Bourdieu, 1990). Thus, while habitus reflects original social experiences, it is capable of transcending the social conditions in which it was produced (Reay, 2004). 
Mindful of the diverse ways scholars have conceptualised habitus, in this article we define habitus as a framework of thinking, feeling and action shaped by social experiences (Bourdieu, 1990). We see habitus as more than a set of individual attributes. It is a constellation of dimensions inextricably linked and related to the field (Colley, 2007). Thus, it is a useful concept for understanding the interplay between individuals and the social world (Dumais, 2002). Habitus offers us a way of understanding how help from others can influence women engineers' propensity to remain in engineering (Ayre et al. 2013; Fouad et al. 2015). While we cannot claim that being exposed to certain kinds of help will categorically lead to women staying on, habitus allows us to consider the interaction between women's thinking and action and their experiences in the workplace, in their decision to remain. In this article, we examine the role of help in the development of the habitus that enables women to persist in engineering.

\section{Research design}

Our study is based on one-to-one interviews conducted with 34 women in early, mid and late career. We formulated the early/mid/late career distinction in relation to the specific dynamics of the engineering profession. Given that it takes four years to get the chartered status and long periods of training is necessary to specialise, we defined early career as less than 10 years in the industry, mid-career as $10-20$ years and late career as over 20 years. We included women from these three career stages because the careers literature suggests that women's interests and preoccupations differ over career stage ( $O^{\prime}$ Neil and Bilimoria, 2005) and we wanted our sample to reflect the range. Ten of our respondents were in early career, 19 in mid-career and five in late career. Our respondents worked for two leading FTSE 100 organisations in the UK. The first organisation, which we refer to by the pseudonym PET, 
supplies fuel, energy, lubricants and petrochemicals to customers around the world. It operates in more than 70 countries worldwide. In the UK, the organisation is based on five sites and we interviewed respondents based in three of these sites. PET prides itself on being a 'forward looking and dynamic' company and has clear goals related to the representation of women at senior levels in the organisation, aiming for $30 \%$ women in senior leadership roles by 2020 . The second organisation, referred to by the pseudonym TTD, is one of the world's leading suppliers of gas and diesel engines. The site at which we conducted the research (which had been acquired by a large multinational in the late 1990s) is primarily a diesel engine manufacturer for several markets including heavy industry and agriculture. The firm was established in a small city in England in the early 20th century and is the largest employer in the town. Many of the engineering employees who work at TTD came through an apprenticeship route and it is common for multiple generations of a family to work for the firm.

Human Resource officers in both companies explained that their organisations were growing, and there was a stated desire to increase the number of women in their engineering workforces. We asked them about the specific gender based retention-based policies they offered. HR professionals from PET and TTD spoke about gender based quota systems for senior posts, part-time and flexible work options for women workers with young children and women's groups for female employees to get to know one another better and discuss common issues of interest. Despite these initiatives, respondents agreed that large cohorts of women continued to leave the profession. They were very interested in our study into staying on. 
Respondents were identified through their organisations. We wrote to HR departments, explaining our interest in studying women's careers in engineering and requesting access to potential respondents. At our request, these gatekeepers invited their female engineering workforce to participate in the study and scheduled interviews with those who expressed interest. The interviews were held onsite in formal meeting rooms. Over 80 per cent of respondents were qualified to graduate level, and 11 had higher degrees. Around 43 per cent of women had children. All three authors (women) conducted the interviews. The interviews were semi-structured, allowing respondents to introduce their own topics while also ensuring that the topics in the guide were covered. During one to one, in-depth interviews, we asked respondents to recount their career stories over time. The women talked about how they got into engineering, their experiences at school, university and the industry, barriers they encountered and how they navigated these. We specifically asked them about persistence in engineering: what they saw as important for women to stay on and why, how they managed to remain in an industry where many women drop out, their relationships with bosses and colleagues, how they felt about their work and working environment and people who helped them to carry on.

Consistent with established practice, interviews were digitally recorded and fully transcribed. Data analysis proceeded at two levels. The first level of coding was descriptive. We examined the data, looking for emergent themes, and for key differences and similarities between them (Gioia et al. 2012). We gave these 'codes' descriptive labels, and assigned data extracts to them. As we worked through the transcripts, we reviewed these descriptors and the data within them, amending them accordingly, to ensure both consistency and manageability. Examples of first level codes included: informal interaction with colleagues; praise from boss; 
observing senior women's behaviour; developing belief in self; feeling like an engineer. These first level codes were local in the sense that they were grounded in women's accounts of their specific work settings. From these descriptive codes, we developed more generic, more conceptual second order themes (Silverman, 2013). These were divided into two broad groupings: types of help (which included different types of help and the various people who provided it), and outcomes. We use the analytical framework we derived to structure the presentation of our findings. We refer to respondents by pseudonyms to maintain their anonymity.

\section{Staying on in engineering: How others help}

\section{Setting the scene}

In the first section, we establish the settings in which our respondents worked. While PET and TTD had some significant differences, they both had intransigently masculine organisational cultures, and in both women said that it was help from others that enabled them to stay on. In the following sections, we examine this 'help' and its implications.

Respondents from PET described their organisation as modern and forward thinking, emphasising its highly educated workforce. Staff discussed how in their eyes PET was a company that treated its staff well, appreciated individuals' contribution and was committed to their development. As Sue comments:

Fundamentally, the organisation is a very professional organisation. I think it is successful.... There is a real widening recognition that we need to attract the broadest range of the best talent available. That is around gender and that's around ethnicity 
in a global market and I think we've got a range of support initiatives that are coming in and being developed as well as already in place.

In contrast, women from TTD talked about their organisation as a traditional male territory, mainly employing engineers from the local area, often through apprenticeship schemes. Although it had progressive HR practices such as flexible working options and enhanced maternity schemes, TTD appeared in many ways to have a more traditional culture than PET. Respondents agreed that in their organisation engineering is seen as 'heavy duty' men's work. For example, one respondent talked about how 'there were men that didn't think women should be here' (Elaine). Although most respondents felt that the culture had improved, a recent recruit commented on how excessively visible she is as a woman in her workplace:

'Like when I go into the factory I get stared at and if you're not expecting that it can be quite scary I think' (Hilda)

Despite these differences between the organisations, within our dataset there was a consensus that engineering is male-dominated and that women, in general, are outsiders, struggling to access social networks and to achieve legitimacy. Echoing the literature noted above, from our respondents' perspective it was a challenging space for women to stay in. That said, the women in our sample had stayed - with 12 interviewees (five from PET and seven from TTD) working in engineering for over 20 years. In the course of the interviews we discussed, at length, what had enabled women to stay on in engineering. Above all else, the help they received from others emerged as paramount. 
Echoing the literature on organisational socialisation (Cooper-Thomas et al. 2014; CooperThomas and Anderson, 2006), it is notable that such help mattered most to respondents in early career. By virtue of their newcomer status (Feldman, 1981; Bauer et al., 1998), such respondents were often unsure about what to do and/or which path to take. Furthermore, we might expect help to be particularly important for early career women engineers than male engineers because women are often isolated in this male dominated engineering industry and excluded from informal networks. Thus for women, there is a significant element of social adjustment (Bauer et al. 2007) for which they require support.

Many of our respondents explained how daunted they were about their career prospects upon entering this male dominated industry, and their ideas about the feasibility of long term engineering careers started to take root early on. Indeed, when we asked mid and late career respondents about they help they received from others and why it mattered, they often reflected on their early career days.

\section{What helps and how?}

Respondents identified four types of help: care and support; feedback; high-level opportunities and responsibilities; and role models. They described the primary outcomes of help in terms of feeling valued; confidence in engineering competence; confidence in going for promotion; and feeling that one can combine work and out of work responsibilities. These led to two secondary outcomes: feeling positive about the organization's climate, and seeing a future in engineering. Taken together, we argue that these outcomes constitute an engineering habitus that enabled respondents to stay on in the field. This framework is summarised in the Table 1. 
(Insert Table 1 here)

\section{Care and peer support}

Care involves respondents' perceptions that others are deeply concerned about them (Kossek et al. 2011), while peer support involves specific emotional and practical help to deal with difficult situations (Chesler et al. 2003; Semmer et al. 2008). All of our respondents talked about how the care and peer support they received from bosses and colleagues critically shaped their decisions to stay in their organisations, and in engineering. Cathy an application engineer at TTD explains:

Like the guy I used to work for. He was really kind. He made me feel like I belong and it makes you feel like really special and it makes you like work hard and it makes you not quit. Like retention in our team is really good. People don't tend to quit. They really feel like they care and I'm like "I'm really special, this guy really likes me."

In contrast to many women engineers who report isolation (Watts, 2010), Cathy felt as if she belonged at TTD. Due to her line manager's caring approach, she felt that she mattered and therefore she was motivated to stay on. In Bourdieusian terms, we can observe how social experiences at a team level triggered an emotional response in Cathy's habitus (Reay, 2004). Importantly, this influenced her decision to remain in the organisation. When women spoke of the care they received from colleagues, this included both women and men, and the colleagues they mentioned worked at different hierarchical levels. It is notable that although Cathy said she felt special, she was not singled out for special attention; rather, her line manager's inclusive approach extended to the whole team. Perhaps unsurprisingly, retention rates in her group were high. While care is arguably important for the retention of both male and female early careerists, we argue that it is particularly important to retain women 
engineers, because they are likely to feel more isolated and vulnerable in organisations in which they are not only in the minority numerically, but also culturally.

While respondents in both organisations emphasised the importance of care, it was more pronounced in the accounts of TTD women. In this traditional organisation, women seemed to encounter a higher level of social exclusion and 'othering' than in PET. However this was countered by the care that they received from immediate supervisors and colleagues which made them feel good about the 'here and now' (Reichers and Schneider, 1990; Veld et al. 2010). Such experiences of being cared for helped respondents to form positive perceptions about their organisation's climate. These arguably served to buffer (Duffy et al. 2002) the detrimental consequences of exclusionary organisational cultures.

Peer support in the form of specific emotional and practical help (Semmer et al. 2008) to deal with adverse situations was also a dominant theme in women's accounts of staying on. This was most pronounced in the accounts of women who worked in more traditionally masculine manual workspaces such as shop floor or offshore sites. In such spaces, young women workers often felt vulnerable, were highly prone to marginalisation, and sometimes even ridicule and harassment. To deal with these challenging situations, peer support (Chesler et al. 2003) was vital and in our data, was seen as a significant factor in women's propensity to stay on. Amelie, a reservoir engineer from PET, explained how she was harassed whilst working offshore. Her team's peer support helped her to deal with this unpleasant situation: I had an issue with one of my colleagues when I was there. He was behaving very inappropriately. One of my colleagues noticed the fact that I was quite disturbed and cold with this guy that we were working with and he asked me why and I told him why 
and then he was like "You need to report all of this stuff, I will back you." so then I reported it and all this sort of stuff, but they (her colleagues) watched out for me which made me stay. I was touched.

Amelie's experience was mirrored by many other PET respondents who worked offshore, and women at TTD with shop floor responsibilities. If her colleagues had not supported her, Amelie may have remained silent and eventually left the organisation. However, although she was disturbed in the beginning, she later felt valued. This is an example of how consecutive experiences can modify the effects of past experiences on the habitus (Bourdieu, 1990). Amelie and many others explained that the emotional support they received from colleagues during difficult times was more than a short-term 'fix'. Rather, they saw it as fundamentally changing the way they felt about the organisation.

\section{Feedback on performance}

Feedback involves receiving regular personalised, constructive praise and criticism about one's performance with specific suggestions on how to move forward. Upon commencing work in the industry, respondents said that they were often unclear about how to approach certain tasks and uncertain whether they were doing things right. While ambiguity might be a common experience for early careerists in any industry (Bauer et al. 2007), we might expect the situation to be worse for women because they are frequently stereotyped as less competent by their male counterparts (Powell et al. 2009), and less confident about their technical competence as a result (Buse et al. 2013). Furthermore, in early career, women were often equivocal about which path to specialise in. Given the negative stereotypes attached to their technical competence, they were extremely keen to get into an area of work 
in which they had particular strengths. For these reasons, women explained that they were desperate for detailed, personalised feedback on their performance.

Approximately one third of our respondents had just that: line managers, who, in their view, went out of their way to explain strengths and weaknesses in their performance, recognise what they did well and offer guidance for further improvement. Significantly, very few respondents talked about feedback as an organisationally-mandated performance management process. Rather, most described it as ad hoc - dependent on the people you were lucky (or unlucky) enough to work for and with. Women explained that feedback not only contributed to their technical ability, but also helped them to feel confident in this ability, thus positively shaping their habitus (Reay, 2016). Jennita, a process engineer from PET explains:

I had no idea of what I was doing and it was a nightmare - the line of work I was assigned to was really complicated - I didn't think that I could last here. The conversations I'd had with her (her line manager) along the lines of... very honest conversations on "This is where you're technically capable, but also this is where you're not," and I could then look at the cold facts of the ratio between the two. We'd had a chat through what support would and wouldn't be available to help with some of those gaps and how much l'd have to learn and how fast l'd have to learn it and we compared it to some of the things I'd done previously that kind of set the ground work and it came out it'd probably work out. It's really worth having someone say "You did that really well - your technical work there was great, but you didn't explain it in a manner that your audience could understand. The very honest feedback I've got from helped me to 
now have the confidence to know what I can already do which I didn't have before and try to swim when thrown in at the deep end.

An important aspect of Jennita's account is the significance she places on her line manager's 'expert credibility' (Hughes, 2011). This seems to come from three sources: her position and understanding of the space, her honesty, and her knowledge of Jennita's work. Importantly, this feedback not only changed the way Jennita felt about her engineering ability, but it also encouraged her to take on new challenges, further cementing her position within the field. By reflecting on her knowledge gaps and learning needs alongside her line manager, Jennita started to develop confidence in her technical ability, and a sense of belonging in engineering.

While Jennita's example illustrates the importance of feedback for the development of confidence in technical ability, others saw it as an important source of career information. Bessie, a manufacturing engineer from TTD, explains:

As a graduate trainee, I did not have a clue about where I was going. I had a really nice lady boss and she kind of took me under her wing and was more open and said "If you ever want a chat about anything then let me know," She's based here at TTD and she's quite high up in the business as well so she'd got quite good knowledge of the business and how it all works. She knew my work and she told me about what I did best what I don't do quite well which was eye opening in knowing what I can do well and deciding on where to go next especially right after the graduate trainee program.

When she commenced work, Bessie was unsure about what her future might hold, and worried about her lack of clarity and direction. However, her line manager's feedback gave 
her the insight she needed to make the next step, and incrementally she began to imagine a future for herself in the field (Dumais, 2002; Cohen, 2014).

Because women often find it difficult to establish themselves in informal organisational networks (Roth, 2006), we might expect explicit feedback from credible others to be extremely important to them. Men in contrast, are likely to access informal feedback by simply engaging in everyday workplace interaction. Women from TTD were more likely than women from PET to link feedback with confidence in technical ability. This might be because these women were repeatedly subjected to negative competency stereotypes by highly critical male colleagues. However, TTD women we interviewed received valuable feedback from their line managers. This not only enabled women to confidently pursue their new roles (Bauer et al. 2007), but also appeared to buffer (Duffy et al. 2002; Wu and Hu, 2009) the effects of negative stereotyping in their heavily masculine organisational cultures and

\section{Opportunities to do higher-level tasks and assume higher level responsibilities}

Discussing their decisions to stay on, respondents highlighted the importance of being given opportunities. These were typically described as invitations, from their managers or other high status colleagues, to get involved in significant projects or to assume higher-level responsibilities. In contrast to the prevailing view of women struggling to accrue social and cultural capital (Roth, 2006) and who thus are limited in their promotion prospects (Hewlett et al. 2008), our respondents talked about being given opportunities to stand in for their line managers and take on new, challenging areas of work. These opportunities not only helped women to hone their expertise, but also gave them the confidence they needed to go for promotion. Because women engineers lacked confidence to take on new roles and 
responsibilities (Hughes, 2011), being given opportunities to do higher-level tasks is arguably more important for them than it is for men. Angelika, a petroleum engineer at PET explains: When I was given this challenge, I really didn't know how to do it. Even when I thought myself I didn't think I could do the job that was being asked of me - it was something he (her manager) usually does. But he just said "Angie, go and enjoy it. You can't do anything wrong. Just try and you can do it. Those were his words to me. So I did it and then realised that I can actually do it - It developed my confidence - I can do higher level work.

Angelika had firmly believed that she could not manage high-level responsibilities. However after standing in for her boss, she came to realise that she could. We see this new sense of confidence as a significant change in Angelika's habitus. In her account, this was a pivotal experience, triggering a shift in how she saw her engineering future.

Suzanne, an engineering team leader at TTD, similarly talked about how a former line manger assigned one of his own tasks to her:

I've had some good managers - Trusting you to do something and then actually like, for example, standing in for my boss and covering the whole of the assembly area when he was off trying to fix another factory and that was a great opportunity. So actually giving you an opportunity to get to know important people and giving you confidence to operate in this environment to take the next step.

Realising that she could manage far greater responsibilities gave Suzanne the confidence to apply for promotion, highlighting how habitus shapes action (Silva, 2016). Suzanne makes the 
point that opportunities also enable women to make themselves visible to important stakeholders and accumulate social capital (Mayrhofer et al. 2004) that they often lack. By undertaking these new responsibilities and roles, women like Suzanne realised that they could work at more senior levels, further cementing their status and encouraging them to stay on.

An important dimension of these tasks was social - by doing them, women were more firmly immersing and embedding themselves within their occupational communities. Opportunities to do challenging work and assume higher-level responsibilities not only helped women to develop confidence in their potential, but also enhanced their social networks and their profiles within the organisation. Arguably, both further cemented respondents' positions in their organizations. While scholars have recognised that confidence is important for women engineers to persist (Ayre et al. 2013), they largely speak about this as an intrinsic trait. Based on our data, we would argue that it is significantly shaped by their social experiences.

\section{Role models who demonstrate work-family balance}

In contrast to the other forms of help noted above, role models had a more passive yet significant influence on incumbents, serving as examples of attitudes and behaviours associated with a particular role. For reasons we have already outlined, respondents (particularly in early career) worried about their chances of lasting in the profession. Women explained that the apparent incompatibility of motherhood and engineering made exit the most realistic option (Bagilhole et al, 2007; Fouad and Singh, 2011). However, exposure to senior women who demonstrated how work and parental responsibilities could be combined significantly changed respondents' worldviews. They learnt that they could be a mother while being an engineer, and thus began to envisage a future for themselves in the profession 
(Dumais, 2002; Clewell and Campbell, 2002; Cohen, 2014). This represents a significant change in habitus, in a sector that most women choose to leave. In the words of Rosie, a PET reservoir engineer:

My boss' boss is a woman. She has a daughter. The team leader for one of the other big assets in the North Sea is a woman and she works four days a week. She's very well respected as an engineer. Very well respected and has an almost exclusive engineering role in a particular department. It feels like women are doing as well as men in National Fuel so there is hope for me -in the beginning I didn't think there was any hope especially if I wanted to have children. But now it makes sense to develop a career here.

Not only was this senior manager a mother, but she was also respected engineer. The presence of such women who had families outside the organisation and were doing important work within it, extended women's horizons. Once Rosie began to see a career in engineering as a possibility, she started to envisage her own career future. As her aspirations developed, exit became less likely.

Likewise, Ellie, a structural engineer at TTD, who was pregnant at the time of the interview, talked about how seeing other women with children in senior positions helped to settle her doubts about combining engineering with motherhood:

I am actually pregnant now, so I'm going off, all being well, in February and you kind of wonder what does that mean in terms of your career. I've got a female colleague who has had a child and is right back in the thick of it again in terms of her career so, you know, that doesn't seem to be stopping her and the company seems to be very 
flexible and seems to manage. Our last two vice-presidents have been female, Glenda and Tracey, and they've both had families. I worked with a colleague who was on an exchange from the US when I was in research and she had three kids. She's doing very, very well and she's very bright and very capable and very good at what she does, so it is possible to do it.

In contrast to women who assumed that combining work and home would be impossible, and so resigned when they had children (Fouad and Singh, 2011), Ellie planned to return to work after maternity leave. Because she saw others doing it, she realised it was feasible and like Rosie, she began to envisage a future for herself in engineering.

The importance of role models for individuals' career progression is well established in the careers literature (Shortland, 2014; Durbin and Tomlinson, 2011). As our data shows, role models worked as symbols of possibility for women engineers, offering inspiration and removing uncertainty (Chung, 2000) by demonstrating that other women have combined a career in engineering with domestic responsibilities. However, it is important to acknowledge the significant difference between being perceived by others as successfully combining home and work and seeing oneself as doing this. Most of the senior women engineers we interviewed declared they had to sacrifice time with their families to make it in engineering: I didn't attend any of my daughter's tennis matches, I was often not there when she needed me, it was the only way to do it (Tania)

Interestingly Tania was seen as a role model by many of the younger women we interviewed from TTD. However, she had a different view of her own experience. She explained that one 
can combine a family with a career in engineering, but it involved making significant compromises on the family front.

\section{Summary of findings}

In sum, the women engineers we interviewed talked about staying on in terms of four forms of personalised help from others: care and peer support (Chesler et al. 2003), feedback about performance, opportunities to take on higher level tasks and responsibilities and exposure to role models who combined work with familial responsibilities (Durbin and Tomlinson, 2011). In line with the literature on organisational socialisation (Cooper-Thomas et al. 2014; CooperThomas and Anderson, 2006), help mattered most to incumbents in early career. The first three forms of help coalesce with ideas of emotional, informational and instrumental support in the social support literature (House et al. 1980).

Our study suggests that 'help' led to primary and secondary outcomes for women engineers which aided the development of an engineering habitus that enabled them to stay on the career pipeline (see Table 1). Care and peer support enabled women engineers to feel valued (Ayre et al. 2013) and consequently feel more positive about their organisation's climate. Opportunities to do higher-level tasks and assume higher level responsibilities enabled them to develop confidence to go for promotion. Feedback about performance enabled women to develop confidence in their engineering competence (Plett et al. 2009) and confidence to go for promotion, consecutively aspiring a future for themselves in engineering. Role models enabled women to feel that they can combine work with out of work responsibilities, again leading to them envisaging a future for oneself in engineering (Buse et al. 2013). Significantly 
the outcomes of help were not mutually exclusive, but linked to each other in dynamic ways - often reinforcing each other.

Women from TTD were more likely than those from PET to emphasise the importance of care and link feedback with confidence in their technical competence. We argued that this reflects the heavily gendered organisational culture of TTD and the potential of 'help from others' to buffer the negative effects of the culture by developing a favourable organisational climate.

\section{Discussion}

In this article we have examined how a group of British women engineers' account for staying on in a male dominated profession that most women choose to leave, a perspective that scholars have begun to examine (Ayre et al. 2013; Fouad et al. 2015). Drawing on the concept of habitus (Reay, 2016; Bourdieu, 2000) we explain the interplay between the individual and the organisational context as fundamental to women's persistence in engineering. Habitus represents socially mediated cognitive structures (Robbins, 1991), dispositions (Swartz, 2002) and embodied interiority (Silva, 2016) including emotions (Reay, 2004) and aspirations (Dumais, 2013) which are constantly in process. It enables us to understand how particular forms of 'help from others' changed women's perceptions about their competence, their potential for leadership, their sense of belonging, their perceptions about the organisation's climate, their perceptions of combining work and non-work responsibilities, their longevity in engineering and led to them develop a set of individual attributes which worked together to make staying on a feasible prospect. We argue that engaging in various forms of help facilitated the development of an engineering habitus. 
The engineering habitus enabled persistence in two key ways. First it buffered the detrimental effects of deeply gendered organisational cultures by shaping favourable 'here and now' perceptions of the immediate atmosphere (Reichers and Schneider, 1990; Veld et al. 2010). For instance, women who felt valued by their colleagues and superiors were able to cope with gender based competency stereotyping (Powell et al. 2009) and harassment (Faulkner, 2007), in contrast to women who choose to leave the profession because of such experiences (see Hewlett et al. 2008). Although line managers and colleagues could not altogether transform the organisation's culture, by providing support they were able to influence the climate in a way that enabled women to survive unwelcoming organisational settings (see Maertz et al., 2003).

Second, an engineering habitus enabled individuals to see themselves as engineers and to feel part of the engineering community. In other words, the habitus transcended the particular set of individual attributes, leading them to realise that they have all that it takes to progress a career in the engineering profession. This realisation made staying on a viable possibility. Our interviewees developed this habitus by mobilising help from others. It was through trying out positions of leadership and jointly reflecting on performance with line managers that respondents came to realise that they could do what was required. Thus individuals actively participated in relationships at work and drew on forms of help to become part of the engineering world. In the case of role models, while this form of help was less direct, respondents who were inspired by role models looked around and applied the experiences of other women who combined work and familial responsibilities to their own lives. This changed their view of engineering and their place within it. 
Habitus allows us to view women engineers' thinking, feeling and action as dynamic, and shaped by processes of workplace exposure (Colley et al. 2007). We cannot claim with certainty that participating in relationships at work and mobilising help from others will result in women developing a habitus that facilitates staying on in engineering. However our findings suggest that help plays a significant role in retention. The engineering habitus we outline is gendered because it applies specifically to women who require a distinct approach to persist in a profession where they are repeatedly cast as outsiders (Hatmaker, 2013; Mills et al. 2008; Watts, 2010). We might expect the durability of the engineering habitus to be dependent on continual participation in workplace relationships and mobilisation of help from others. Our findings suggest that this might be especially important during early career when people are unsure about their place in the context.

Capturing the relationship between women engineers and the organisational contexts in which they work, and the implications of this on-going relationship for career-making, the concept of engineering habitus makes a significant contribution to HRM. HRM deals with the enduring problems of employee retention, formulating various policies and practices to increase the likelihood of retaining skilled employees in the long term. However, critics have taken issue with the lack of contextualisation within the field of HRM, and with prescriptions for practice that are based upon over-simplified analyses of the social world (Keegan and Boselie (2006; Peltonen and Vaara, 2012). We suggest that an understanding of habitus and its importance in career development is an important development in HRM theorising.

Habitus provides a useful conceptual vehicle for examining the interplay between individuals and their social contexts, and the consequences of this interaction for both individuals and 
organisations (in our case here, for women engineers' staying on). This helps us to understand the persistence and reproduction of gendered barriers and identify spaces for change. Notably, our study highlights that the presence, absence or development of habitus cannot be assumed, nor can it be 'read off' from an examination of policies or formal practices. Rather, to understand its workings, we need to examine individuals' accounts of their lived experiences. Scholars have argued that HRM policy should be based not on generic prescription, but on contextualised understanding (Boxall et al. 2007). We agree. On the basis of our analysis, we suggest that an appreciation of habitus can lead to the development of HRM policies and practices that recognise how people live and make sense of their organizational lives, and contribute to how they imagine their career futures.

In the next section we consider specific implications of our analysis for HRM practice.

\section{Implications for HRM, limitations and directions for future research}

Our findings showed how help from others buffers the negative effects of deeply gendered organisational cultures and facilitates women engineers' persistence in 'chilly' (Bailyn, 2003) work settings that many women choose to leave. Based on our findings we suggest that support should not be random, dependent on the people one happens to work for and with. Rather all employees should have equal access to support in their organisations and enjoy the benefits of supportive relationships with superiors and co-workers. Support is important for both male and female early careerists who are often unsure about what to do and/or which path to take and unsure about their place in the context. 
We outline HRM practices which may facilitate supportive relationships. First, raising the visibility of female role models is important to project a positive image of female engineers within the organisation and potentially challenge powerful stereotypes. Second, support can be at the centre of organisations' training initiatives, provided through mechanisms such as ensuring that personalised feedback is given, particularly to early career engineers; encouraging people to assume positions of leadership; making colleagues feel valued; and providing support in a way that nurtures independence. Third, organisations can introduce a 'buddy scheme' for early careerists assigning them to a sympathetic incumbent who can provide information, introduce them to other colleagues who are important to their role and help them understand the culture of the organisation, together helping them to settle in and establish themselves. Fourth, organisations' reward systems can facilitate informal support by recognising and rewarding employees who demonstrate supportive behaviours, thus maximising the instrumental value of proactive helping. Providing employees with the motivation, knowledge and opportunity to perform supportive behaviours is extremely important in male dominated, masculine organisational contexts because, even when the overall organisational culture is unwelcoming to women workers, the climate created by coworkers and managers can make a difference and facilitate retention. When more people engage in supportive behaviours, there will be a spillover effect for the organisation as a whole (Chiaburu and Harrisson, 2008; Organ et al. 2006).

We recognise the limitations of our work. Our findings are based on a small group of women engineers in male dominated engineering fields. The experiences of our respondents may not reflect the experiences of all women engineers, in these or other sectors. We therefore invite scholars to further develop our work. 
We invite scholars to further develop our work. In this article, we focus on the role of 'help from others' in the development of the engineering habitus. We argued that the engineering habitus facilitates women's persistence in the engineering field. It is also important to examine the role of early socialisation experiences in the development of an engineering habitus. It is well known that early socialisation experiences have tended to discourage women from seeing themselves as potential engineers, but it would be interesting to explore whether people can draw on their early socialisation experiences to navigate gendered barriers in the engineering field. Furthermore, it is also important to examine what an engineering habitus looks like for men. Our focus on women is justified as they are a minority in this field, but comparative studies are crucial to further our understanding of the engineering habitus.

We also outline directions for future research for HRM scholars. HRM scholars can take our study as a point of departure to examine the extent to which various HRM policies and practices actually encourage supportive relationships in the workplace, how this happens, and whether there are there any significant mediating factors or instances where support is paradoxically hindered through these practices. These questions should be answered in order to fully understand how HRM can influence structures of informal support within organisations.

\section{References}

Ayre, M., Mills, J. Gill, J. (2013) Yes, I do Belong': The Women who Stay in Engineering. Engineering Studies, 5(3), 216-232. 
Bagilhole, B., Powell, A., Barnard, S. and Dainty, A. (2007) Researching Cultures in Science, Engineering and Technology: an analysis of current and past literature. Resource Centre for Women in Science, Engineering and Technology. Bradford: UK

Bauer, T. N., Bodner, T., Erdogan, B., Truxillo, D. M. and Tucker, J. S. (2007). Newcomer adjustment during organizational socialization: A meta-analytic review of antecedents, outcomes, and methods. Journal of Applied Psychology, 92, 707-721.

Bennet, M.M and Beehr, T.A (2013) Collegial Relationships and Social Support in Organizations. In R.L. Morrison and H.D. Cooper-Thomas (eds) Relationships in Organizations A Work Psychology Perspective. Palgrave Macmillan.

Bourdieu, P. (1984) Distinction (London, Routledge and Kegan Paul).

Bourdieu, P. (1990). In Other Words._Polity Press, Cambridge

Bourdieu, P. (1988) Vive la Crise! for heterodoxy in social science, Theory and Society, 19(5), 773- 88.

Boxall, P., Purcell, J. and Wright, P.M. (2007) The Oxford handbook of human resource management. Oxford University Press.

Buse, K. Bilimoria, D. Perelli, S. (2013) Why they stay: women persisting in US engineering careers, Career Development International, 18(2): 139 - 154.

Chesler, N. C., Boyle Single, P. and Mikic, B. (2003). On belay: Peer mentoring and adventure education for women faculty in engineering. Journal of Engineering Education, 92(3), 257262.

Chiaburu, D.S. and Harrisson, D.A. (2008) Do Peers Make the Place? Conceptual Synthesis and Meta-Analysis of Coworker Effects on Perceptions, Attitudes, OCBs, and Performance. Research paper. Mays Business School. Texas A\&M University. 
Clewell, B. and Campbell, J. R. (2002) Taking stock: Where we've been, where we are, where we're going. Journal of Women and Minorities in Science and Engineering, 8, 255-284.

Colley, H., James, D., Diment, K. and Tedder, M. (2007) Learning as becoming in vocational education and training: class, gender and the role of vocational habitus, Journal of Vocational Education \& Training, 55:4, 471-498.

Cooper-Thomas, H., Paterson, N., Stadler, M. and Saks, M. (2014) The relative importance of proactive behaviors and outcomes for predicting newcomer learning, well-being and work engagement. Journal of Vocational Behavior, 8 (2): 318-331

Cooper-Thomas, H.; Anderson, N. (2006) Organizational socialization: A new theoretical model and recommendations for future research and HRM practices in organizations. Journal of Managerial Psychology, 21 (5): 492-516.

DiMaggio, P. (1979) Review Essay: On Pierre Bourdieu, American Journal of Sociology, 84(6), 1460-74.

Duffy, M. K., Ganster, D. C., \& Pagon, M. (2002). Social undermining in the workplace. Academy of Management Journal, 45, 331-351.

Dumais, S. (2002) Cultural Capital, Gender and School Success: The Role of Habitus. Sociology of Education, 75, 44-68.

Durbin, S. and Tomlinson, J. (2014) Female part-time managers: careers, mentors and role models. Gender, Work and Organization, 21, 308-320

Ehrich, L. C. (2008) Mentoring and women managers: another look at the field. Gender in Management: An International Journal, 23(7). pp. 469-483.

Faulkner, W. (2009) Doing gender in engineering workplace cultures. 1. Observations from the field. Engineering Studies 1 (1), 3-18. 
Fouad, N.A, Singh, R., Cappaert, K, Chang, W. and Wan, M. (2015) Comparison of women engineers who persist in or depart from engineering. Journal of Vocational Behavior, 92, 7993.

Fouad, N. A., and Singh, R. (2011) Stemming the Tide: Why Women Leave Engineering. Milwaukee: University of Wisconsin.

Gill, J., Mills, J. E. Franzway, S. and Sharp, R. (2008) Oh you must be very clever! High-achieving women, professional power and the ongoing negotiation of workplace identity. Gender and Education, 20 (3): 223-236.

Gioia, D., Corley, K. and Hamilton, A. (2012) Seeking qualitative rigor in inductive research: Notes on the Gioia methodology. Organizational Research Methods, 16(1): 15-31

Greed, C. (2000) Women in the construction professions: achieving critical mass, Gender, Work and Organization, 7 (3), 181-96.

Hammersley, M. and Atkinson, P. (1997). Ethnography: Principles in practice (2nd ed.), London: Routledge.

Harris, J.I., Winskowski, A.M. and Engdahl, B.E. (2007), "Types of workplace social support in the prediction of job satisfaction", Career Development Quarterly, 56(2), pp. 150-156.

Hatmaker, D.M (2013) Engineering Identity: Gender and Professional Identity Negotiation among Women Engineers. Gender, Work and Organization, 20(4), 382-396.

Hayton, J. C., Carnabuci, G. and Eisenberger, R. (2012). With a little help from my colleagues: a social embeddedness approach to perceived organizational support. Journal of Organizational Behavior, 33, 235-249

Heilman, M. E. (2012) Gender stereotypes and workplace bias. Research in Organizational Behaviour, 32, 113-135. 
Heilman, M. E. and Eagly, A. H. (2008) Gender stereotypes are alive, well, and busy producing workplace discrimination. Industrial and Organizational Psychology, 1, 393-398.

Hewlett, S. A., Luce, C.B., Servon, L.J., Sherbin, L., Shiller, P., Sosnovich, E. and Sumberg, K. (2008) The Athena Factor: Reversing the Brain Drain in Science, Engineering and Technology." HBR (Harvard Business Review) Report, Harvard: Center for Work-Life Policy.

House, J.S. (1981) Work stress and social support. Reading, MA: Addison Wesley.

House, J. S., Umberson, D. and Landis, K. R. (1988). Structures and processes of social support. Annual Review of Sociology, 14, 293-318.

Hughes, R. (2011) Are the Predictors of Women's Persistence in STEM Painting the Full Picture? A Series of Comparative Case Studies. International Journal of Gender, Science and Technology, 3 (3): 547-570.

Janssen, S. Vuuren, M.N. and de Jong, M.D.T (2015) Informal Mentoring at Work: A Review and Suggestions for Future Research. International Journal of Management Reviews, Vol. 00, $1-20$.

Johnson, P. and Duberley, J. (2000) Understanding Management Research: An introduction to Epistemology. London: Sage.

Keegan, A. and Boselie, B (2006) The Lack of Impact of Dissensus Inspired Analysis on Developments in the Field of Human Resource Management. Journal of Management Studies. 43 (7): 491-1511.

King, N. (2004). Using templates in the thematic analysis of text. In C. Cassell and G. Symon (eds), Essential Guide to Qualitative Methods in Organizational Research, London: Sage.

King, A. (2000). Thinking with Bourdieu Against Bourdieu: A 'Practical' Critique of the Habitus. Sociological Theory, 18 (3): 417-433.

Martin, J. L. (2003) What is field theory? American Journal of Sociology, 109(1), 1-49. 
Mayrhofer, W., lellatchitch, A., Meyer, M., Steyrer, J., Schiffinger, M. and Strunk, G. (2004) Going beyond the individual. Journal of Management Development, 23, 870-884.

Mills, J. E., Mehrtens, V., Smith, E. and Adams, V. (2008) CREW revisited in 2007 the year of women in engineering: an update on women's progress in the Australian engineering workforce. Engineers Australia: Canberra, Australia.

Ng, T. W. H. and Sorensen, K. L. (2008). Toward a further understanding of the relationships between perceptions of support and work attitudes: A meta-analysis. Group and Organization Management, 33, 243-268.

O’Neil, D.A. and Bilimoria, D. (2005) Women's career development phases: Idealism, endurance, and reinvention. Career Development International, 10(3), 168 - 189.

Organ, D. W., Podsakoff, P. M. and MacKenzie, S. B. (2006). Organizational citizenship behavior: Its nature, antecedents, and consequences. Thousand Oaks, CA: Sage.

Peltonen, T. and Vaara, E. (2012) Critical approaches to comparative HRM. In C. Brewster and W. Mayrhofer (eds), Handbook of research on comparative human resource management. Edward Elgar, Cheltenham, pp. 69-89.

Plett, M., Hawkinson, C., Van Antwerp, J.J. Wilson, D. and Bruxvoort, C. (2011) Engineering identity and the workplace persistence of women with engineering degrees. Paper presented at the 2011 ASEE Annual Conference, 26-29 June, Vancouver, Canada.

Pierrakos, O., Beam, T.K., Constantz, J., Johri, A. and Anderson, R. (2009) On the Development of a Professional Identity: Engineering Persisters vs Engineering Switchers. Conference Paper in Proceedings - Frontiers in Education Conference. San Antonio, Texas.

Powell, A., Bagilhole, B. and Dainty, A. (2009) How Women Engineers Do and Undo Gender: Consequences for Gender Equality. Gender, Work and Organisation 16(4), 411-428. 
Reay, D. (2016) Habitus and the psychosocial: Bourdieu with feelings. Cambridge Journal of Education. 45(1), 9-23.

Reay, D. (2004) It's All Becoming a Habitus': Beyond the Habitual Use of Habitus in Educational Research. British Journal of Sociology of Education, 25 (4), 431-444.

Reichers, A.E. and Schneider, B. (1990). 'Climate and culture. An evolution of constructs', in B. Schneider (ed.), Organizational Climate and Culture, San Francisco, CA: Jossey-Bass Publishers.

Robbins, D. (1991) The work of Pierre Bourdieu: Recognizing society. Buckingham: Open University Press.

Roth, L.M. (2006) Selling Women Short: Gender and Money on Wall Street. Princeton University Press, Princeton, NJ

Servon, L.J. and Vissers, M.A. (2011) Progress hindered: The retention and advancement of women in science, engineering and technology careers. Human Resource Management Journal 21(3),272- 284 .

Sias, P. M. (2005). Workplace relationship quality and employee information experiences. Communication Studies, 56, 375-395.

Singh, V., Bains, D. and Vinnicombe, S. (2002) Informal mentoring as an organisational resource. Long Range Planning, 35, 389-405.

Silva, E. (2016) Unity and fragmentation of the habitus. The Sociological Review, 64, 166-183. Spitzmuller, M. and Van Dyne, L. (2013) Proactive and reactive helping: Contrasting the positive consequences of different forms of helping. Journal of Organizational Behaviour, 34, $560-580$.

Sullivan, A. (2001) Cultural Capital and Educational Attainment'. Sociology, 4(4), 893-912. 
Swartz, D.L. (2002) The Sociology of Habit: The Perspective of Pierre Bourdieu. Occupation, Participation and Health. 22 (1), 61S-69S.

Tyler, T. R. and Blader, S. L. (2000). Cooperation in groups: procedural justice, social identity, and behavioral engagement. Philadelphia, PA: Psychology Press.

Van Yperen, N. W. and Hagedoorn, M. (2003). Do high job demands increase intrinsic motivation or fatigue or both? The role of job control and job social support. Academy of Management Journal, 46, 339-348.

Veld, M., Paauwe, J. and Boselie, P. (2010) HRM and strategic climates in hospitals: does the message come across at the ward level? Human Resource Management Journal, 20(4): 339356

Watts, J. H. (2007) Porn, pride and pessimism: experiences of women working in professional construction roles. Work, Employment and Society, 21 (2), 297-314.

Watts, J. H. (2010) Now you see me, now you don't: The visibility paradox for Women in a Male-Dominated Profession. In P. Lewis and R. Simpson (eds.), Revealing and Concealing Gender: Issues of Visibility in Organisations. Palgrave Macmillan.

$\mathrm{Wu}, \mathrm{T}$. and $\mathrm{Hu}, \mathrm{C}$. (2009). Abusive supervision and employee emotional exhaustion: Dispositional antecedents and boundaries. Group \& Organization Management, 34(2), 143169. 


\section{Table 1: Help and outcomes}

\begin{tabular}{|c|c|c|c|}
\hline Experience of help & Providers & Primary Outcomes & Secondary Outcomes \\
\hline $\begin{array}{l}\text { - Care and peer support } \\
\text { (Care involves perceptions of receiving } \\
\text { profound concern from others, while peer } \\
\text { support involves receiving specific emotional } \\
\text { and practical help to deal with difficult } \\
\text { situations) }\end{array}$ & $\begin{array}{l}\text { Male and female colleagues in } \\
\text { different departments and } \\
\text { hierarchical levels } \\
\text { Line managers: usually male }\end{array}$ & $\begin{array}{l}\text { - Feeling valued } \\
\text { (Feeling that you matter and that you belong) }\end{array}$ & \\
\hline $\begin{array}{l}\text { - Feedback on performance } \\
\text { (Receiving personalised constructive praise } \\
\text { and criticism about one's performance on a } \\
\text { regular basis with specific suggestions on how } \\
\text { to move forward) }\end{array}$ & Line managers - usually male & $\begin{array}{l}\text { - Confidence in engineering competence } \\
\text { (Believing that one has the ability to do } \\
\text { engineering work) } \\
\text { - Confidence to go for promotion } \\
\text { (Believing that one has the potential to } \\
\text { assume broader managerial responsibilities) }\end{array}$ & $\begin{array}{l}\text { - Feeling positive about the } \\
\text { organisation's climate. }\end{array}$ \\
\hline $\begin{array}{l}\text { - Opportunities to do higher-level tasks } \\
\quad \text { and assume higher level responsibilities. } \\
\text { (Offers and invitations from significant } \\
\text { personnel to be involved in critical projects } \\
\text { and/or assume higher-level responsibilities) }\end{array}$ & Line managers - usually male & $\begin{array}{l}\text { - Confidence in engineering } \\
\text { competence } \\
\text { (Believing that one has the ability to do } \\
\text { engineering work) } \\
\text { Confidence to go for promotion } \\
\text { (Believing that one has the potential to } \\
\text { assume broader managerial responsibilities) }\end{array}$ & $\begin{array}{l}\text { - Seeing a future for one's } \\
\text { self as an engineer }\end{array}$ \\
\hline $\begin{array}{l}\text { - Providing role models who combined } \\
\text { work and parental responsibilities } \\
\text { (Demonstrating that women can still be } \\
\text { mothers and achieve success in engineering) }\end{array}$ & Other women in engineering & $\begin{array}{l}\text { Feeling that one can combine work } \\
\text { and out of work responsibilities. }\end{array}$ & \\
\hline
\end{tabular}

